\title{
Respostas fisiológicas de genótipos de fava (Phaseolus lunatus L.) submetidas ao estresse hídrico cultivadas no Estado do Ceará
}

\author{
Silvio Gentil Jacinto Júnior ${ }^{1}$ (D), João Gutemberg Leite Moraes ${ }^{1}$, Fred Denilson Barbosa da Silva ${ }^{4}$, \\ Bruno do Nascimento Silva ${ }^{3}$, Geocleber Gomes de Sousa ${ }^{4}$, Laís Lacerda Brasil de Oliveira ${ }^{1}$, \\ Rosilene Oliveira Mesquita ${ }^{2}$ \\ ${ }^{1}$ Mestrado em Climatologia e Aplicações nos Países da CPLP e África, \\ Universidade Estadual do Ceará, Fortaleza, CE, Brasil. \\ ${ }^{2}$ Departamento de Fitotecnia, Universidade Federal do Ceará, Fortaleza, CE, Brasil. \\ ${ }^{3}$ Departamento de Biologia Vegetal, Universidade Federal de Viçosa, Viçosa, MG, Brasil. \\ ${ }^{4}$ Instituto de Desenvolvimento Rural, Universidade da Integração Internacional da Lusofonia \\ Afro-Brasileira, Redenção, CE, Brasil.
}

Recebido em: 30 de Abril de 2019 - Aceito em: 21 de Junho de 2019

\begin{abstract}
Resumo
Das espécies do gênero Phaseolus, a fava é a mais tolerante à seca se comparada com os feijões comuns. Apesar da sua importância, ela tem sido pouco estudada, necessitando de pesquisas aplicadas à cultura para maior compreensão dos mecanismos envolvidos na resposta ao déficit hídrico. Este estudo avalia a tolerância de quatro genótipos de fava cultivados no Ceará quanto a sua resistência ao estresse hídrico. O experimento foi realizado em um delineamento inteiramente casualizado, no esquema fatorial $4 \times 3 \mathrm{em}$ que o primeiro fator foi constituído pelos genótipos: 'Branca', 'Mulatinha', 'Preta' e 'Coquinho Laranja'; o segundo por três regimes hídricos: irrigado, déficit moderado e déficit severo; com cinco repetições. As plantas foram conduzidas em vasos até o estádio fenológico $\mathrm{V}_{3}$ onde foram avaliados os seguintes parâmetros fisiológicos: taxa fotossintética $(A)$, condutância estomática (gs), relação Ci/Ca, Transpiração $(E)$, eficiência no uso da água (EUA), eficiência no uso da água intrínseca (EUA int), eficiência instantânea de carboxilação (EiC) e taxa de transferência de elétrons (ETR). Sem comprometer seu metabolismo, o genótipo Coquinho Laranja foi mais tolerante ao déficit hídrico, evidenciando maior produtividade fotossintética, associadas à alta eficiência no uso da água pelo fechamento dos seus estômatos com redução da transpiração.
\end{abstract}

Palavras-chave: Phaseolus lunatus L., trocas gasosas, tolerância à seca.

\section{Physiological responses of fava genotypes (Phaseolus lunatus L.) submitted to water stress cultivated in the state of Ceará}

\begin{abstract}
Among species of the genus Phaseolus, fava is the most tolerant to drought when compared to common beans. Despite its importance, it has been little studied, requiring applied research to the culture for a better understanding of the mechanisms involved in the response to the water deficit. This study evaluates the tolerance of four fava genotypes grown in Ceará on their resistance to water stress. The experiment was carried out in a completely randomized design, in the 4 x 3 factorial scheme in which the first factor was constituted by the cultivars: 'Branca', 'Mulatinha', 'Preta' and 'Coquinho Laranja'; the second by three water regimes: irrigated, moderate deficit and severe deficit; with five replicates. (A), stomatal conductance (gs), $\mathrm{Ci} / \mathrm{Ca}$ ratio, Transpiration (E), water use efficiency, efficiency in the use of intrinsic water (USA int), instantaneous carboxylation efficiency (EiC) and electron transfer rate (ETR). Without compromising its metabolism, the genotype Coquinho Laranja was more tolerant to the water deficit, evidencing higher photosynthetic productivity, associated with the high efficiency in the use of water by the closure of its stomata with reduction of transpiration.
\end{abstract}

Keywords: Phaseolus lunatus L., gas exchange, drought tolerance.

Autor de correspondência: Silvio Gentil Jacinto Junior, silviogentil@hotmail.com. 


\section{Introdução}

O cultivo da fava (Phaseolus lunatus $\mathrm{L}$.) na região Nordeste do Brasil corresponde a mais de $90 \%$ do que é produzido nacionalmente (Ibge, 2018). É a segunda leguminosa do gênero Phaseolus, logo depois do feijão comum (P. vulgaris L.), com importância socioeconômica, visto que sua composição química atende às necessidades proteicas das comunidades em que estão inseridas, sendo consumida nas formas de grãos maduros ou verdes (Vieira, 1992).

Embora essa cultura assuma importância econômica em vários estados, como na Paraíba (responsável por cerca de $50 \%$ da produção nacional), ela possui uma baixa produtividade se comparada à região Sul do país, o que demonstra a falta de investimentos em tecnologias de manejo e melhoramento genético da cultura (Santos et al., 2002); além de programas de manejo da nutrição, da irrigação, fitossanitário, dentre outros que tornem sua produtividade mais elevada; e das irregularidades encontradas nas precipitações pluviométricas oriundas de inúmeras variáveis meteorológicas (Alves et al., 2008).

Conforme Santos et al. (2011), o impacto das mudanças climáticas sobre as culturas tem sido objeto de estudo em todo o mundo, uma vez que estas variáveis estão intimamente ligadas. Elas partem da dicotomia entre as alterações no clima e a necessidade cada vez maior de se produzir alimentos. Muitos desses trabalhos vêm alertando que as condições climáticas futuras poderão impactar substancialmente a produtividade agrícola.

Cabe destacar que a instabilidade climática afeta as culturas agrícolas em quase todas as regiões produtoras do Brasil, com períodos de excessos de pluviosidade e em outras de deficiência hídrica. Esta última é uma condição comum na região Nordeste do Brasil, sendo um dos fatores que comumente reduzem a produtividade dos feijões da espécie P. vulgaris (Mendes et al., 2007). Neste cenário, a fava se destaca como uma das culturas que, mesmo cultivada em regime de sequeiro e com o uso de poucas tecnologias, é mais resistente à seca e ao excesso de umidade do que o feijão comum (Vieira, 1992; Oliveira et al., 2014).

O cultivo de genótipos mais tolerantes em períodos de déficit hídrico (estresse), bem como o desenvolvimento de pesquisas e tecnologias que auxiliem o manejo das plantas em tolerar períodos prolongados de estiagem, serão essenciais na manutenção da produção agrícola brasileira e mundial, em níveis que possam alimentar a população em constante crescimento.

Bianchi et al. (2016) afirmam que entre os fatores abióticos que podem causar estresse em vegetais estão respectivamente: água, radiação, temperatura, gases e minerais. O estresse hídrico pode ocorrer através da falta de água (déficit hídrico), ou por excesso de água (inundação), sendo o primeiro mais recorrente nas regiões semiáridas.
Para garantir o fornecimento de água por mais tempo aos seus tecidos, as plantas reduzem a sua área de transpiração, diminuindo a sua expansão celular e, consequentemente, sua área foliar (perda de biomassa com redução do crescimento da parte aérea) (Anjum et al., 2011). Essa resposta fisiológica é relevante, pois promove uma diminuição na interface planta/atmosfera com a redução da transpiração, com consequente queda na assimilação fotossintética (aspecto negativo para a produção). Movidas pela redução na transpiração, essas ações defensivas favorecem uma conservação de água no solo por um período mais prolongado de tempo (Taiz et al., 2017).

A redução da condutância estomática é influenciada pelo fechamento dos estômatos para evitar a perda de água o que leva a uma diminuição na concentração interna de $\mathrm{CO}_{2}(\mathrm{Ci})$ e na transpiração $(E)$ que, como consequência, limita a quantidade de gás carbônico $\mathrm{CO}_{2}$ requerida para a fotossíntese (Oliveira et al., 2005). Esse parâmetro é importante, pois permite identificar se a fotossíntese está sendo limitada por meio de restrições estomáticas ou por alterações quanto à morfologia dos estômatos e do mesófilo que podem atingir, inclusive, os cloroplastos. Essas alterações denotam que há pouca disponibilidade de gás carbônico para o processo fotossintético, havendo limitação bioquímica da fotossíntese (Chaves et al., 2009).

A eficiência no uso da água (EUA) e a eficiência no uso da água intrínseca (EUAint) são índices que permitem definir como os estômatos estão sendo controlados durante o processo metabólico (Manalavan et al., 2009). Dessa forma, essas variáveis têm apresentado uma grande importância na categorização de genótipos tolerantes à seca, quando estes são submetidos a condições de escassez e reidratação (Tezara et al., 2008).

Diante da importância da fava para a região Nordeste do Brasil, torna-se imprescindível a realização de pesquisas visando avaliar o desempenho de cultivares desenvolvidas para o cultivo em regime de sequeiro, frente às limitações hídricas impostas que ocorrem em diferentes fases de crescimento.

Dessa forma, este trabalho consiste em analisar a tolerância à seca de quatro genótipos de fava, cultivados no Estado do Ceará, através de parâmetros fisiológicos quando estes estão submetidos a condições de escassez hídrica e reidratação.

\section{Materiais e Métodos}

$\mathrm{O}$ experimento foi realizado e conduzido em telado protegido pertencentes à área experimental do Departamento de Fitotecnia do Centro de Ciências Agrárias CCA, da Universidade Federal do Ceará - UFC, localizada no Campus do Pici (latitude $3^{\circ} 44^{\prime} 24,4^{\prime \prime}$ S e longitude $38^{\circ}$ 34'32,0" W) em Fortaleza - CE, no período de novembro de 2017 a janeiro de 2018 com temperatura média em 
torno de 24,8 a $31,9^{\circ} \mathrm{C}$ e umidade relativa do ar em torno de 75\% (INMET, 2018).

O substrato para o plantio foi preparado a partir da mistura de areia fina peneirada em malha com abertura de $2 \mathrm{~mm}$ de diâmetro, húmus de minhoca e vermiculita (todos adquiridos no comércio local) nas proporções de 6:3:1, respectivamente, até tornar-se homogêneo. Uma amostra do solo foi coletada e levada ao Laboratório de Solos/ Água do Departamento de Ciências do Solo da Universidade Federal do Ceará, onde as análises foram realizadas. Os resultados da análise físico-química da amostra foram: $\mathrm{pH}$ em $\mathrm{H}_{2} \mathrm{O}=6,10 ; \mathrm{P}$ assimilável $=319,00 \mathrm{mg} / \mathrm{kg}$; $\mathrm{K}^{+}=0,72 \mathrm{cmol}_{\mathrm{c}} / \mathrm{kg} ; \mathrm{Na}^{+}=0,49 \mathrm{cmol}_{\mathrm{C}} / \mathrm{kg} ; \mathrm{H}^{+}+$ $\mathrm{Al}^{+3}=0,99 \mathrm{cmol}_{\mathrm{c}} / \mathrm{kg} ; \mathrm{Al}^{+3}=0,40 \mathrm{cmol}_{\mathrm{c}} / \mathrm{kg} ; \mathrm{Ca}^{+2}=3,20$ $\mathrm{cmol}_{\mathrm{C}} / \mathrm{kg} ; \mathrm{Mg}^{+2}=2,80 \mathrm{cmol}_{\mathrm{C}} / \mathrm{kg} ; \mathrm{SB}=7,20 \mathrm{cmol}_{\mathrm{c}} / \mathrm{kg}$; $\mathrm{CTC}=8,20 \mathrm{cmol}_{\mathrm{c}} / \mathrm{kg}$ e matéria orgânica $=1,87 \mathrm{dag} / \mathrm{kg}$.

$\mathrm{O}$ delineamento experimental utilizado foi o inteiramente casualizado, em esquema fatorial $4 \times 3$, sendo quatro genótipos de fava (Fava Branca (FB); Fava Coquinho Laranja (FC); Fava Mulatinha (FM) e Fava Preta (FP) e três regimes hídricos (irrigado, moderado e severo) com 5 repetições, sendo a unidade experimental constituída de uma planta por vaso, totalizando sessenta vasos. Os quatro genótipos de fava foram oriundos de diferentes municípios do Ceará, a saber: Fava Branca (FB) de Crato; Fava Coquinho Laranja (FC) de Icó; Fava Mulatinha (FM) de Senador Pompeu e Fava Preta (FP) de Araripe.

A semeadura ocorreu no dia 15 de novembro de 2017, em que foram colocadas quatro sementes por vaso de cada genótipo através do método de semeadura direta. Foi realizado o desbaste manualmente, dez dias após a emergência (DAE), deixando-se uma planta por vaso. Durante a condução da cultura foram retiradas as ervas daninhas que nasciam nos vasos; e irrigações diariamente (com aproximadamente $300 \mathrm{~mL}$ de água) até que todos os genótipos atingissem a fase $\mathrm{V}_{3}$ de crescimento (segundo nó - abertura do $3^{\circ}$ trifólio), com imposição do estresse hídrico a partir dessa etapa de acordo com cada tratamento.

A imposição do estresse hídrico ocorreu aos 28 DAE quando todas as plantas já se encontravam na fase de crescimento $\mathrm{V}_{3}$. Os genótipos foram submetidos a três condições hídricas. Na condição irrigada $\left(T_{1}\right)$, os genótipos foram irrigados conforme a necessidade hídrica da cultura durante todo o ciclo; no déficit moderado $\left(\mathrm{T}_{2}\right)$, as plantas de fava foram cultivadas com redução de $50 \%$ de sua necessidade hídrica e no déficit severo $\left(T_{3}\right)$ foi suspensa totalmente a irrigação. Essa metodologia foi adaptada do trabalho de Vale et al. (2012) e Chavarria et al. (2015) modificando-se o estádio fenológico em que a cultura se encontrava e os regimes de irrigação. Os tratamentos foram mantidos por um período de sete dias encerrando-se com análise de trocas gasosas a fim de verificar se as culturas suportariam novo ciclo de estresse.
A segunda análise de trocas gasosas foi realizada aos 35 DAE (07 dias após a imposição do estresse). A partir dos resultados das análises foi decidido manter o estresse hídrico por mais 06 dias (totalizando 13 dias). Aos 41 DAE foi retomada a irrigação de todos os genótipos até a sua capacidade de campo. O objetivo do retorno da irrigação consistiu em: além de simular o efeito da volta da chuva após um longo período de estiagem; verificar se os genótipos sob estresse severo respondiam ao retorno da irrigação. A última análise ocorreu aos $48 \mathrm{DAE}$ (sete dias após o retorno da irrigação) marcando o encerramento das análises fisiológicas.

Para mensuração das trocas gasosas, utilizou-se um analisador de gases por infravermelho portátil (IRGA), modelo Li - 6400XT (Portable Photosynthesis System LI) da LICOR ${ }^{\circledR}$, utilizando-se radiação fotossinteticamente ativa (PAR) constante $\left(1200 \mu \mathrm{mol}\right.$ fótons $\left.\mathrm{m}^{-2} \mathrm{~s}^{-1}\right)$, com concentração constante de $\mathrm{CO}_{2}(400 \mathrm{ppm})$, na temperatura e umidade ambiente. Foram avaliadas as taxas de assimilação fotossintética líquida por unidade de área $(A)$, condutância estomática $\left(g_{s}\right)$, taxa de transpiração $(E)$ e razão entre a concentração interna e externa de $\mathrm{CO}_{2}(\mathrm{Ci} /$ Ca) (Machado et al., 2005; Melo et al., 2009).

De posse destes dados, foram quantificadas a eficiência do uso da água (EUA), eficiência no uso da água intrínseca (EUA int), eficiência instantânea de carboxilação (EiC) e taxa de transferência de elétrons (ETR). Procedeu-se às aferições das respectivas variáveis, no estádio V3, período anterior a prefloração e a formação de vagens, adotando-se, como critério, a terceira folha totalmente expandida, contada a partir do ápice do ramo principal (Ferraz et al., 2012).

Os dados coletados foram submetidos à Análise de Variância - ANOVA, e quando apresentaram significância (interações entre os genótipos e os tratamentos) a $p \leq 0,05$; foram comparadas, posteriormente, as médias pelo teste de Tukey $(\mathrm{p} \leq 0,05)$. As análises estatísticas e os gráficos foram obtidos utilizando os programas Sisvar ${ }^{\circledR}$ (Ferreira, 2011) e SigmaPlot@14.0 (Systat Software, Chicago, IL, USA) respectivamente.

\section{Resultados e Discussão}

Após sete dias de imposição do estresse hídrico, os diferentes regimes de irrigação influenciaram o comportamento de todos os genótipos em relação aos parâmetros fisiológicos: taxa de assimilação fotossintética $(A)$, condutância estomática $(g s)$, relação da concentração interna e externa de $\mathrm{CO}_{2}(\mathrm{Ci} / \mathrm{Ca})$, eficiência no uso da água (EUA; (A/E)), eficiência no uso da água intrínseca (EUA int; (A/ gs)) e eficiência instantânea de carboxilação (EiC, (A/Ci)). Não houve interação significativa apenas para a variável transpiração $(E)$.

No regime irrigado, a fava Branca obteve os resultados menos expressivos para a fotossíntese, diferindo-se da 
Mulatinha e apresentando valores ligeiramente inferiores aos da Preta e Coquinho Laranja, sem diferir estatisticamente delas. Para o regime moderado, a fava Mulatinha e Coquinho Laranja apresentaram os melhores valores, diferenciando-se da Branca e da Preta. Para a fava Coquinho Laranja não houve diferença estatística entre os regimes irrigado e moderado. No regime severo, foram observados os menores valores para a fava Branca diferenciando-se estatisticamente das demais. A partir da análise do gráfico pode-se verificar que houve uma redução na taxa de assimilação fotossintética à medida que o estresse hídrico é imposto (Fig. 1A).

Quanto à condutância estomática ( $g \mathrm{~s})$, a Coquinho Laranja e a Mulatinha apresentaram maiores valores no tratamento controle (diferindo-se estatisticamente da Preta e da Branca); para o moderado, a fava Preta diferenciou das demais por apresentar o menor resultado, evidenciando rápido fechamento estomático. Sob estresse hídrico severo, todos os genótipos apresentaram os mesmos valores em relação à condutância estomática não se diferindo estatisticamente (Fig. 1B).

A relação da concentração interna e externa de $\mathrm{CO}_{2}$ $(\mathrm{Ci} / \mathrm{Ca})$ não foi afetada para todos os genótipos no regime irrigado. Entretanto, a relação $\mathrm{Ci} / \mathrm{Ca}$ reduziu para a fava Preta, diferindo-a estatisticamente das demais no moderado; e no severo esse mesmo comportamento foi observado para os genótipos: Mulatinha, Preta e Coquinho, diferindo-se esses da Branca que apresentou valores constantes nos diferentes regimes de irrigação (Fig. 1C). Contrapondo-se às tendências naturais dos processos fisiológicos em relação às trocas gasosas, a variável transpiração $(E)$ não diferiu significativamente quando comparados os genótipos versus os diferentes níveis de estresse. No entanto, pode-se observar uma tendência de redução na transpiração em decorrência da diminuição da condutância estomática (Fig. 1D).

Essa redução da taxa de assimilação de $\mathrm{CO}_{2}$ com a imposição dos diferentes regimes de tratamento podem ser explicadas devido ao comprometimento da absorção de gás carbônico em resposta ao fechamento dos estômatos, comprovadas pela diminuição nos valores de condutância estomática ou, possivelmente, ocasionada por algum dano direto do próprio déficit hídrico sobre o metabolismo fotossintético (Endres et al., 2010). A abertura dos estômatos favorece a absorção de gás carbônico; ao se fecharem, economizam água por diminuição da transpiração restringindo o risco de desidratação. A condutância estomática é reduzida à medida que a disponibilidade de água no solo diminui, restringindo a taxa de transpiração como resposta ao fechamento dos estômatos (Inoue; Martins, 2006). O intuito dessa resposta fisiológica é restringir a perda de água, com consequente redução da transpiração e absorção de gás carbônico $\left(\mathrm{CO}_{2}\right)$, acarretando, como consequência, uma redução acentuada da taxa fotossintética e da acumulação de fotoassimilados (Taiz et al., 2017).
Houve diferenças significativas entre os genótipos na relação entre as concentrações de gás carbono interno e externo $(\mathrm{Ci} / \mathrm{Ca})$ com a imposição do estresse severo. Através dessa relação pode-se constatar a eficiência ou ineficiência das reações metabólicas de fixação de carbono, sendo que quanto mais se aproximar de 1,0, menos eficiente é esse processo, em razão de problemas na maquinaria fotossintética. Através da análise da razão $\mathrm{Ci}$ / Ca é possível inferir se está ocorrendo limitação difusional ou bioquímica (Guerra et al., 2017).

As alterações na fotossíntese líquida $(A)$ podem ser ocasionadas por limitações estomáticas como: mudanças na abertura dos estômatos e resistência ao influxo de $\mathrm{CO}_{2}$; ou limitações nas reações bioquímicas como a inibição não estomática da fotossíntese em consequência do comprometimento da regeneração da Rubisco (Ribulose 1,5bifosfato carboxilase-oxigenase). A diminuição da relação $\mathrm{Ci} / \mathrm{Ca}$ com a imposição do estresse hídrico severo indica que os genótipos: Mulatinha, Preta e Coquinho Laranja mantém a eficiência do seu aparato bioquímico a fim de evitar a redução de sua assimilação de carbono. Em situações de escassez hídrica, plantas que conseguem perceber os estímulos ambientais e convergem rapidamente esforços para reduzirem a perda de água por meio dos seus estômatos, mantendo-as assim pelo menos temporariamente, apresentam bom comportamento fisiológico ao manterem taxas fotossintéticas razoáveis (Nóbrega et al., 2001).

Uma variável importante que descreve esse comportamento é a eficiência no uso da água (EUA). Nos tratamentos irrigado e moderado não houve diferença estatística entre os genótipos. No regime severo, a fava Coquinho e a Branca apresentaram os melhores e os piores resultados, respectivamente, se diferindo estatisticamente da Branca e da Preta. A Mulatinha apresentou valores inferiores as da Coquinho e levemente superiores as da Preta não se diferindo estatisticamente delas (Fig. 2A).

Para a eficiência no uso da água intrínseca (EUA int) não houve diferença estatística para o regime irrigado. No moderado, a fava Preta apresentou valores superiores as favas Branca, Mulatinha e Coquinho. No severo, apenas a Branca apresentou valores inferiores às demais, diferindose estatisticamente. Para ela não houve diferença em relação aos regimes de irrigação (Fig. 2B).

Os genótipos não diferiram estatisticamente no regime irrigado quanto à taxa instantânea de carboxilação (EiC). No moderado, a fava Branca apresentou os piores valores, diferindo-se estatisticamente da Coquinho e da Mulatinha. No severo, a Branca e a Preta diferenciaram-se da Coquinho, que não diferiu estatisticamente da Mulatinha (Fig. 2C).

A taxa de transporte de elétrons (ETR) decresceu à medida que o estresse hídrico foi imposto. Nos tratamentos irrigado e moderado a fava Coquinho apresentou os melhores valores diferenciando-se, estatisticamente, da 


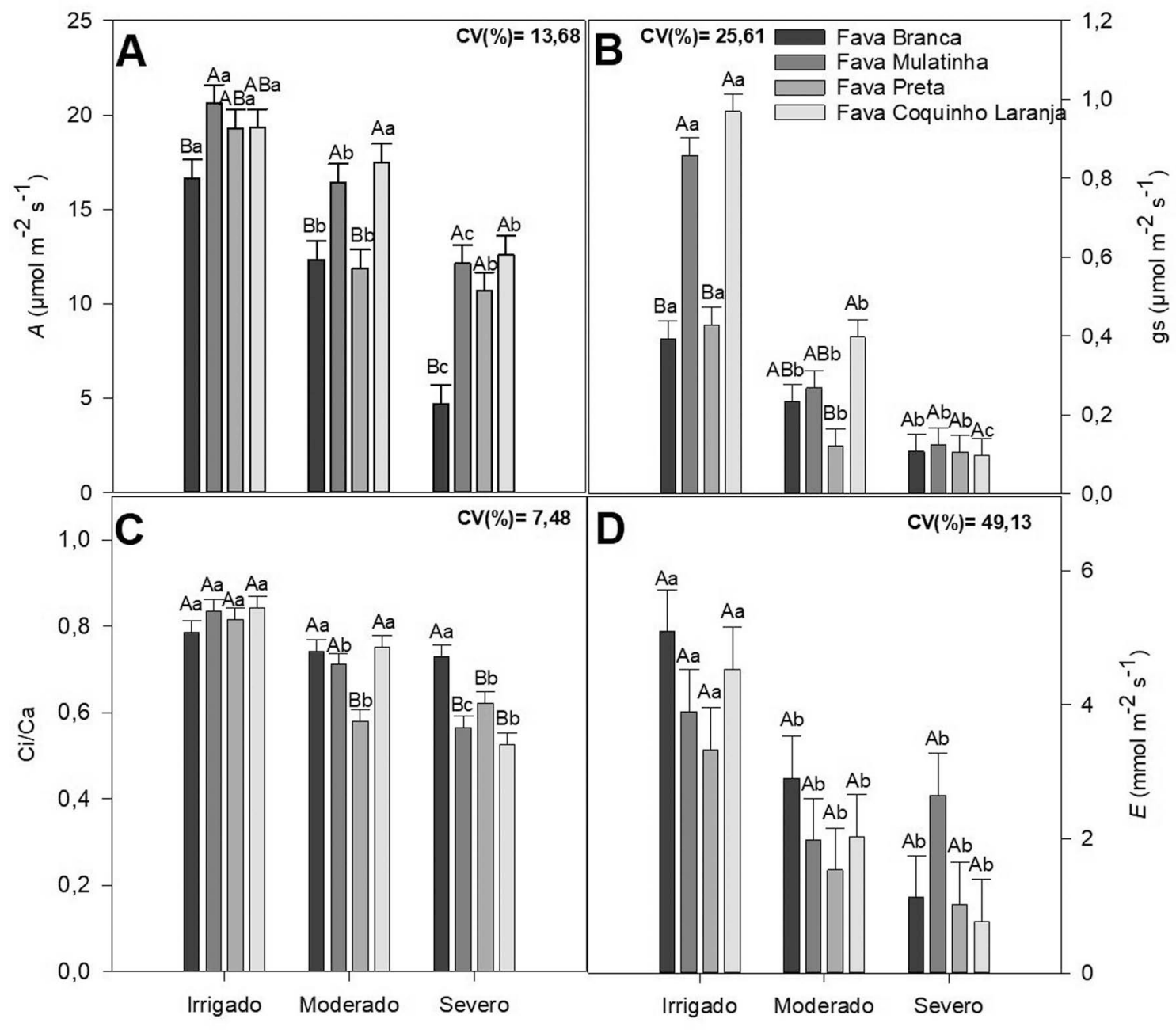

Figura 1 - Influência do déficit hídrico na taxa de assimilação fotossintética (A), condutância estomática (B), relação entre a concentração interna e externa de gás carbônico (C) e transpiração (D) nas cultivares: fava Branca, Mulatinha, Preta e Coquinho.

fava Preta. No déficit severo, as cultivares responderam de forma similar (Fig. 2D).

A eficiência no uso da água (EUA) relaciona o somatório de biomassa acumulada pela unidade de água utilizada. Fisiologicamente isso pode ser definido como a relação entre a taxa de carbono assimilada pela planta através da fotossíntese $(A)$ e a quantidade de água perdida através da transpiração $(E)$. Dessa forma, a EUA está associada ao conjunto de mecanismos de resiliência adotadas pelas plantas em condições de seca (Fageria et al., 1984). O aumento acentuado da EUA para o genótipo Coquinho indica que este consegue assimilar com boa eficiência o gás carbônico com menor perda de água. O que denota que este genótipo é mais tolerante ao estresse hídrico.

Conforme Chaves et al. (2003), o aumento da eficiência no uso da água intrínseca (EUA int) entre as favas Mulatinha e Coquinho é resultado da relação não linear entre a assimilação de carbono $(A)$ e a condutância esto- mática $(g \mathrm{~s})$. Isso indica que a perda de água ocorre antes e mais intensamente do que a inibição da fotossíntese, evidenciando que mesmo com os estômatos abertos e havendo perda de água através da transpiração, a planta consegue fixar carbono para produção de fotoassimilados. Quanto à eficiência instantânea de carboxilação (EiC), de acordo com Larcher (2004), uma elevação da concentração interna de gás carbônico (Ci) nas plantas sob estresse pode estar relacionada ao fato do $\mathrm{CO}_{2}$ não está sendo fixado na etapa carboxilativa nas células do mesófilo. Isso indica que existem restrições na fase metabólica do ciclo de Calvin-Benson, reduzindo a taxa fotossintética e comprometendo a etapa bioquímica da fotossíntese, comportamento observado para a fava Branca.

Os valores relativos à taxa de transferência de elétrons (ETR) diminuíram juntamente com a condutância estomática ( $g \mathrm{~s})$. Essa relação direta sugere que o fechamento dos estômatos, ocorrido durante a suspensão da irrigação, tenham levado a um decréscimo da 


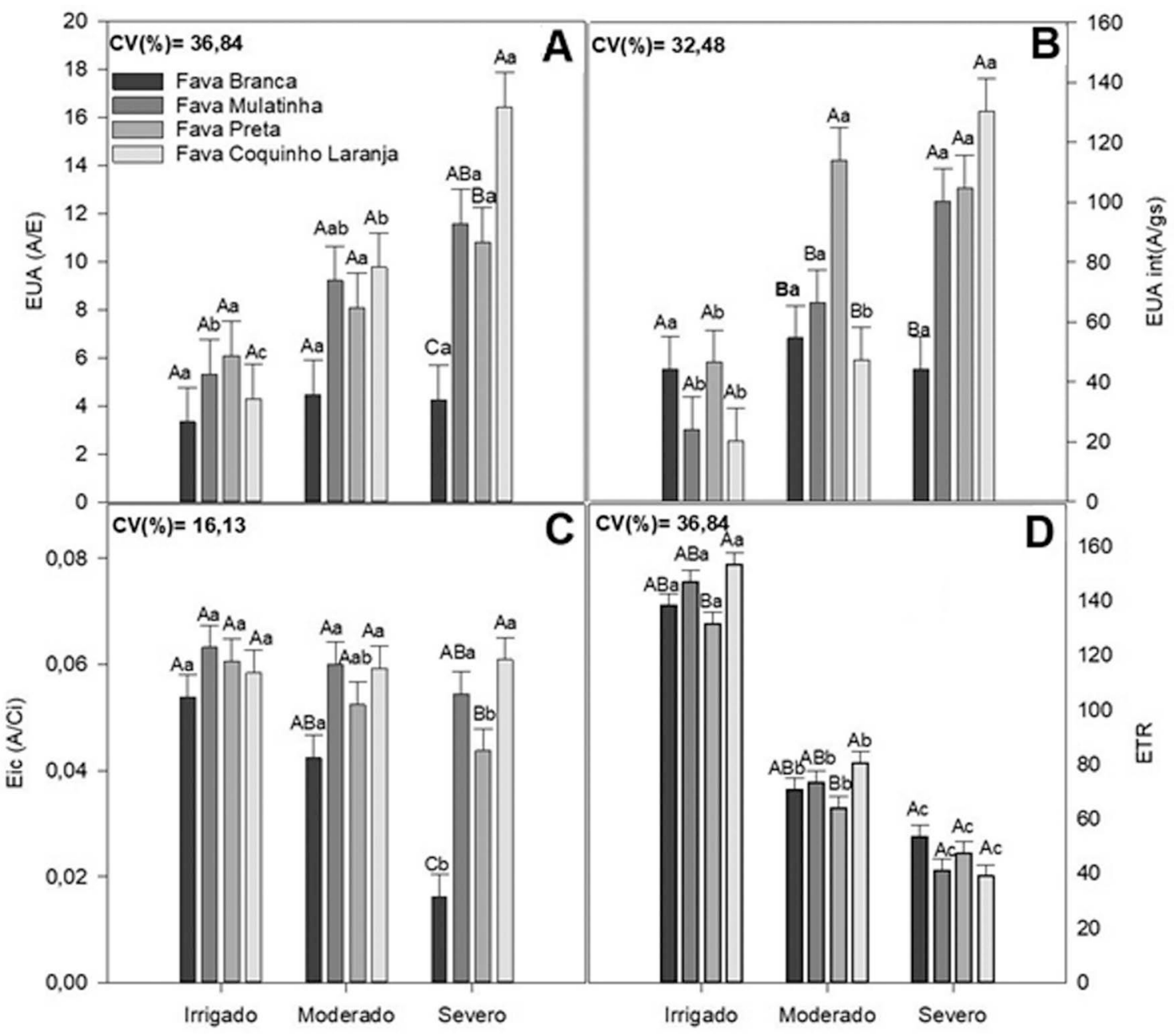

Figura 2 - Influência da escassez hídrica sobre a eficiência no uso da água (A), eficiência no uso da água intrínseca (B), taxa instantânea de carboxilação (C) e taxa de transferência de elétrons (D) nas cultivares: fava Branca, Mulatinha, Preta e Coquinho.

concentração intercelular de $\mathrm{CO}_{2}$ e na redução de assimilação desse gás diminuindo o fluxo de elétrons não cíclico. Dessa forma, uma grande proporção do fluxo de elétrons é desviada da assimilação de gás carbônico (A) para a redução de oxigênio aumentando a peroxidação lipídica e, consequentemente, seu potencial para danos no aparato fotossintético (Lawlor, 1995; Lemos Filho, 2000).

Com o retorno da irrigação, o genótipo Coquinho Laranja, sob estresse severo, conseguiu igualar sua taxa de assimilação de carbono com as plantas sob déficit moderado, não diferindo estatisticamente delas. Isso indica que esse genótipo apresenta indícios de recuperação fotossintética. Já a fava Mulatinha, em regime moderado, obteve valores relativos à fotossíntese líquida equiparados aos do regime irrigado, indicando retomada total de seu metabolismo fotossintético. A reidratação não apresentou resultados significativos para a fava Branca e a Preta. (Fig. 3A). A condutância estomática não foi influenciada pelo fim do estresse nos regimes moderado e severo em todos os genótipos (Fig. 3B). A transpiração acompanha o fechamento dos estômatos $(g s)$, sendo reduzida para evitar a perda de água (Fig. 3D). A relação $\mathrm{Ci} / \mathrm{Ca}$ manteve-se constante para todos os genótipos nos diferentes tratamentos (Fig. 3C).

Com o processo de reidratação, a fava Branca manteve seus valores relativos à transpiração constantes em todos os tratamentos. Para que os genótipos Mulatinha e Coquinho mantivessem suas taxas de acumulação de carbono no regime moderado semelhantes estatisticamente aos do irrigado e do moderado e severo semelhantes aos do controle, respectivamente; foi necessário manter baixos valores de gs e $E$. A tendência desses dois genótipos é que após mais alguns dias de irrigação possam reestabelecer seu aparato fotossintético equiparando-se aos do nível irrigado. A não significância na relação $\mathrm{Ci} /$ $\mathrm{Ca}$ dos regimes moderado e severo em relação ao irrigado, denota uma melhora no aparato fotossintético das culturas, indicando não haver limitação bioquímica entre os genótipos (Chaves et al., 2009; Manalavan et al., 2009). 


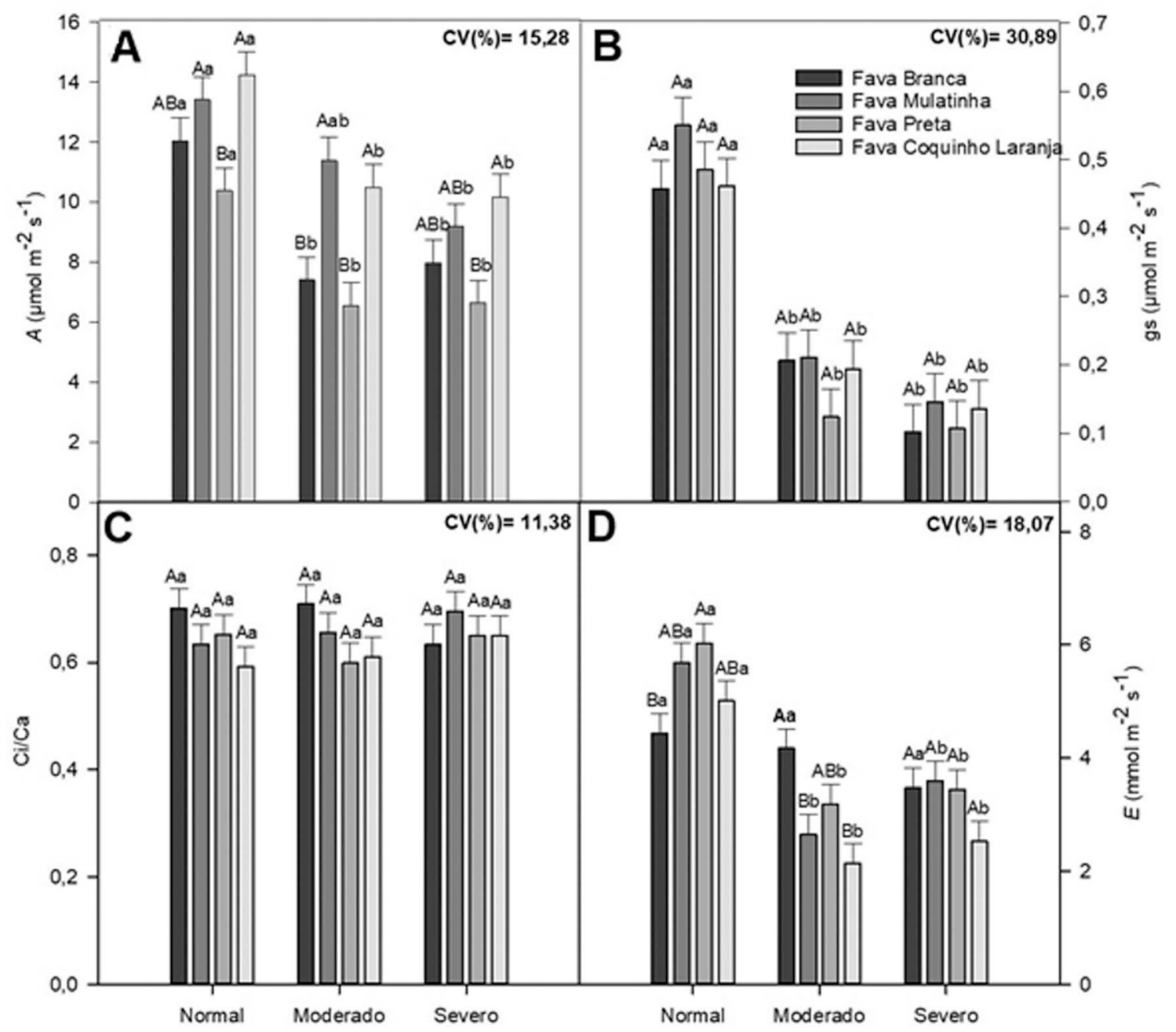

Figura 3 - Influência do retorno da irrigação na taxa de assimilação fotossintética (A), condutância estomática (B), relação entre a concentração interna e externa de gás carbônico (C) e transpiração (D) nas cultivares: fava Branca, Mulatinha, Preta e Coquinho.

Em relação à eficiência no uso da água (EUA), observam-se valores superiores aos do irrigado na Mulatinha e na Coquinho no regime moderado, e somente da última no regime severo (Fig. 4A). A eficiência no uso da água intrínseca (EUAint) aumentou de forma linear em todos os genótipos (Fig. 4B). Para a eficiência instantânea de carboxilação (EiC) observou-se uma melhora nos genótipos Mulatinha e Coquinho Laranja em relação aos demais no regime moderado (Fig. 4C). A taxa de transferência de elétrons (ETR) manteve-se constante nos regimes moderado e severo para todos os genótipos avaliados (Fig. 4D).

Os maiores valores de EUA e EUA int evidenciada para a fava Coquinho, principalmente nos níveis severos, indicam que esse genótipo consegue manter processos fisiológicos e metabólicos essenciais para o seu desenvolvimento em condições de estresse e reidratação, favorecendo a manutenção da sua produtividade.
A melhora na eficiência instantânea de carboxilação confirma que mesmo com uma menor concentração de gás carbônico interna (Ci) é possível haver assimilação de carbono. Esse comportamento mostra uma recuperação da capacidade bioquímica dos genótipos Mulatinha e Coquinho por meio da redução na produção de espécies reativas de oxigênio (ERO) ou por uma melhora na regeneração da Rubisco (Silva et al., 2012; Zhang et al., 2016).

A taxa de transferência de elétrons (ETR) não foi influenciada pela reidratação. Essa limitação ocorre devido aos baixos valores encontrados para a condutância estomática. Com a normalização da condutância estomática a tendência é que os genótipos aumentem a produção de proteínas que atuam diretamente na fotossíntese, como a Rubisco ativase e a proteína D1, auxiliando na transferência de elétrons durante a cadeia transportadora de elétrons por um aumento na eficiência do fotossistema II (Hayano-Kanashiro et al., 2009). 


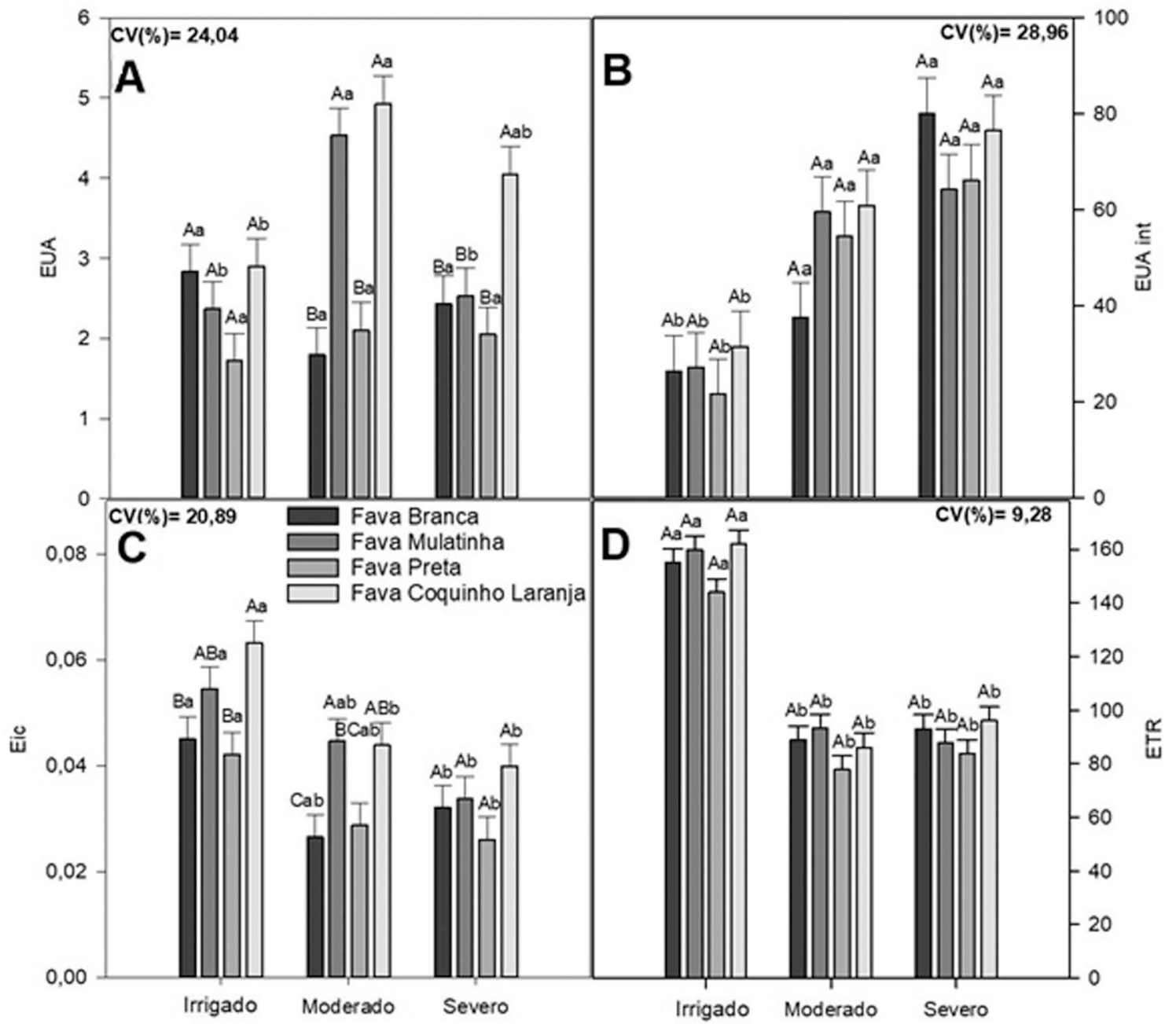

Figura 4 - Influência do retorno da irrigação sobre a eficiência no uso da água (A), eficiência no uso da água intrínseca (B), taxa instantânea de carboxilação (C) e taxa de transferência de elétrons (D) nas cultivares: fava Branca, Mulatinha, Preta e Coquinho.

A reidratação por um período de cinco dias após 13 dias de estresse não foi suficiente para recuperar totalmente os genótipos. Entretanto, observa-se uma pequena melhora na transpiração $(E)$ e na relação $\mathrm{Ci} / \mathrm{Ca}$ em comparação com o regime irrigado, indicando que o progressivo aumento da irrigação poderia recuperar os genótipos Coquinho Laranja e Mulatinha.

Os valores relativos à EUA e EUA int permanecem aumentados com a reidratação, sobretudo no regime severo. A EiC e a ETR aumentam progressivamente indicando recuperação do aparato fotoquímico e bioquímico dos mesmos genótipos citados anteriormente. $\mathrm{O}$ efeito sinérgico entre os parâmetros biométricos e fisiológicos permitem inferir que a fava Coquinho Laranja apresenta maior tolerância ao estresse hídrico e, portanto, melhor capacidade de adaptação à seca em relação aos demais genótipos.

A partir desses resultados, pode-se inferir que as respostas adaptativas de ordem fisiológica e morfológica apresentadas pelas plantas durante um período de déficit hídrico sofrem variações de acordo com a espécie, cultivar, estádio de desenvolvimento da planta, duração e intensidade da escassez hídrica. Todos esses mecanismos levam a redução na perda de água aumentando a capacidade de resiliência da planta (Levitt, 1980). Sendo que os genótipos que não sofrerem grandes reduções das características estudadas nessas condições, devem ser classificados com tolerantes ao estresse hídrico, como evidenciado para a fava Coquinho Laranja.

\section{Conclusões}

A fava 'Coquinho Laranja' demonstrou maior tolerância à seca em relação às demais, quando submetidas a diferentes regimes de irrigação. Os parâmetros morfofisiológicos que justificam esse resultado são: o genótipo apresentou maiores valores de fotossíntese associados a menores valores de transpiração, revelando uma maior 
eficiência do processo fotossintético com redução da perda de água; não ocorrendo inibição bioquímica da fotossíntese.

Após a reidratação, o genótipo 'Coquinho Laranja' exibiu indícios de recuperação evidenciados pela equiparação da assimilação de gás carbônico nos tratamentos moderado e severo; manutenção de suas taxas de condutância estomática e transpiração; melhores resultados em relação à eficiência no uso da água com aumento da taxa de eficiência instantânea de carboxilação.

\section{Referências}

ALVES A.U.; OLIVEIRA, A.P.; ALVES, A.U.; DORNELAS, C. S.M.; ALVES, E.U.; CARDOSO, E.A.; OLIVEIRA, A.N. P.; CRUZ, I.S. Lima beans production and economic revenue as function of organic and mineral fertilization. Journal of the Brazilian Association for Horticultural Science, v. 26, n. 2, p. 251-254, 2008.

ANJUM, S.A.; XIE, X.; WANG, L.; SALEEM, M.F.; MAN, C.; LEI, W. Morphological, physiological and biochemical responses of plants to drought stress. African Journal of Agricultural Research, v. 6, n. 9, p. 2026-2032, 2011.

BIANCHI, L.; GERMINO, G.H.; SILVA, M. de A. Adaptação das Plantas ao Déficit Hídrico. Acta Iguazu, v. 5, n. 4, p. 15-32, 2016.

CHAVARRIA, G; DURIGON, M.R; KLEIN, V.A; KLEBER, H. Restrição fotossintética de plantas de soja sob variação de disponibilidade hídrica. Revista Ciência Rural, Santa Maria, v. 45, n. 8, p. 1387-1393, 2015.

CHAVES, M.M.; MAROCO, J.P.; PEREIRA, J.S. Understanding plant responses to drought - from the genes to the whole plant. Functional Plant Biology, v. 30, p. 239-264, 2003.

CHAVES, M.M.; FLEXAS, J.; PINHEIRO, C. Photosynthesis under drought and salt stress: regulation mechanisms from whole plant to cell. Annals of Botany, v. 103, n. 4, p. 551560, 2009.

ENDRES, L.; SOUZA, J.L. de; TEODORO, I.; MARROQUIM, P.M.G.; SANTOS, C.M. dos; BRITO J.E.D. de. Gas exchange alteration caused by water deficit during the bean reproductive stage. Revista Brasileira de Engenharia Agrícola e Ambiental, v. 14, p. 11-16, 2010.

FAGERIA, N.K.; BALIGAR, V.C.; CLARK, R.B. Physiology of Crop Production, New York: The Haworth Press Inc, 1984. 345p.

FERRAZ, R.L. de S.; MELO, A.S. de.; SUASSUNA, J.F.; BRITO, M.E.B. de.; FERNANDES, P.D.; NUNES JÚNIOR, E. da S. Trocas gasosas e eficiência fotossintética em ecótipos de feijoeiro cultivados no semiárido. Pesquisa Agropecuária Tropical, v. 42, n. 2, p. 181-188, 2012.

FERREIRA, D.F. SISVAR: a computer statistical analysis system. Ciência e Agrotecnologia, v. 35, n. 6, p. 1039-1042, 2011.

GUERRA, A.M.N. de M.; COSTA, A.C.M.; TAVARES, P.R. de F. Atividade fotossintética e produtividade de alface cultivada sob sombreamento. Revista Agropecuária Técnica, v. 38, n. 3 , p. $125-132,2017$.
HAYANO-KANASHIRO, C.; CALDERÓN-VÁZQUEZ, C.; IBARRA-LACLETTE，E.; HERRERA-ESTRELLA，L.; SIMPSON, J. Analysis of gene expression and physiological responses in three mexican maize landraces under drought stress and recovery irrigation. Plos one, v. 2, n. 1, p. 1-19, 2009.

INSTITUTO BRASILEIRO DE GEOGRAFIA E ESTATÍSTICA - IBGE. Bancos de Dados Agregados. Disponível em: http://www.sidra.ibge.gov.br/. Acesso em: 2 jan. 2018.

INSTITUTO NACIONAL DE METEOROLOGIA - INMET. Estação Meteorológica de Observação de Superfície Nacional. Disponível em: http://www.inmet.gov.br/sim/ sonabra/dspDadosCodigo.php?ODIzOTc $=$. Acesso em: 10 jun. 2018.

INOUE, M.T.; MARTINS, E.G. Variação sazonal da fotossíntese e clorofila em progênies de Grevillea robusta Cunn. Revista Ciências Exatas e Naturais, v. 8, p. 113-124, 2006.

LARCHER, W. Ecofisiologia vegetal. In: A Planta Sob Estresses. São Carlos: Rima, p. 341-448, 2004.

LAWLOR, D.W. The effects of water deficit on photosynthesis. In: SMIRNOFF, N. (Ed.). Environmental and Plant Metabolism-fFexibility and Acclimation, Oxford: Bios Scientific Publisher, p. 129-160, 1995.

LEMOS FILHO, J.P. Fotoinibição em três espécies de cerrado (Annona crassifolia, Eugenia dysenterica e Campomanesia adamantium) na estação seca e na chuvosa. Revista Brasileira de Botânica, v. 23, p. 45-50, 2000.

LEVITT, J. Response of Plants to Enviropmental Stress. New York: Academic Press, 1980. 606p e 667p.

MACHADO, E.C.; SCHMIDT, P.T.; MEDINA, C.L.; RIBEIRO, R.V. Respostas da fotossíntese de três espécies de citros a fatores ambientais. Pesquisa Agropecuária Brasileira, v. 40, n. 12, p. 1161- 1170, 2005.

MANAVALAN, L.P.; GUTTIKONDA, S.K.; TRAN, L.S.P.; NGUYEN, H.T. Physiological and molecular approaches to improve drought resistance in soybean. Plant e Cell Physiology, v. 50, p. 1260-1276, 2009.

MELO, A.S de.; SILVA JUNIOR, C.D da.; FERNANDES, P.D.; SOBRAL, L.F.; BRITO, M.E.B.; DANTAS, J.D.M. Alterações das características fisiológicas da bananeira sob condições de fertirrigação. Ciência Rural, v. 39, n. 3, p. 733741, 2009.

MENDES, R.M.S.; TÁVORA, F. J. A. F.; PINHO, J. L.N.; PITOMBEIRA, J. B. Relações fonte-dreno em feijão-decorda submetido à deficiência hídrica. Ciência Agronômica, v. 38, p. 95-103, 2007.

NÓBREGA, J.Q.; RAO, T.V.R.; BELTRÃO, N.E.M.; FIDELIS FILHO, J.; NASCIMENTO, S.P.; BASTOS, E.A.; ARAÚJO, E.C.E.; FREIRE FILHO, I.F.R Análise de crescimento do feijoeiro submetido a quatro níveis de umidade do solo. Revista Brasileira de Engenharia Agrícola e Ambiental, v. 5, n. 3, p. 437-443, 2001.

OLIVEIRA, A.D.; FERNANDES, E.J.; RODRIGUES, T.J.D. Condutância estomática como indicador de estresse hídrico em Feijão. Engenharia Agrícola, v. 25, p. 86-95, 2005.

OLIVEIRA, A.E.S.; SIMEÃO, M.; MOUSINHO, F.E.P.; GOMES, R.L.F. Desenvolvimento do feijão-fava (Phaseolus lunatus L.) sob déficit hídrico cultivado em ambiente protegido. Holos, ano 30, v.1, p. 144, 2014. 
SANTOS, D; CORLETT, F.M.F.; MENDES, J.E.M.F.; WANDERLEY JÚNIOR, J.S.A. Produtividade e morfologia de vagens e sementes de variedades de fava no Estado da Paraíba. Pesquisa Agropecuária Brasileira, Brasília, DF, v. 37, n. 10, p. 1407-1412, 2002.

SANTOS, R.S. dos.; COSTA, L.C.; SEDIYAMA, G.C.; LEAL, B.G.; OLIVEIRA, R.A.de; JUSTINO, F.B. Avaliação da relação seca/produtividade agrícola em cenário de mudanças climáticas. Revista Brasileira de Meteorologia, v. 26, n. 2, p. 313-321, 2011.

SILVA, N.E.; RIBEIRO, R.V.; SILVA, L.F.; VIEIRA, S.A.; PONTE, L.F.A.; SILVEIRA, J.A.G. Coordinate changes in photosynthesis; sugar accumulation and antioxidative enzymes improve the performance of Jatropha curcas plants under drought stress. Biomass and Bioenergy, v. 45, p. 270-279, 2012.

SYSTAT SOFTWARE, Inc. SigmaPlot 14 for Windows. 2017. Disponível em: https://systatsoftware.com/sp/download. html. Acesso em: 2 jun. 2018.

TAIZ, L.; ZEIGER, E.; MØLLER, I. M.; MURPHY, A. Fisiologia Vegetal. 6. ed. Porto Alegre: Artmed, 2017. 918p.
TEZARA, W.; DRISCOLL, S.; LAWLOR, D.W. Partitioning of photosynthetic electron flow between $\mathrm{CO}_{2}$ assimilation and $\mathrm{O}_{2}$ reduction no sunflower plants under water deficit. Photosynthetica, v. 46, n. 1, p. 127-134, 2008.

VALE do, N.M; BARILI, L.D; ROZZETO, D.S; STINGHIN, J. C; COIMBRA, J.L.M; GUIDOLIN, A.F; KÖOP, M.M. Avaliação para tolerância ao estresse hídrico em feijão. Revista Biotemas, v. 25, n. 3, p. 135-144, set. 2012.

VIEIRA, R.F.A cultura da fava. In: VIEIRA, C. Leguminosas de grãos: importância econômica na agricultura e na alimentação humana. Informe Agropecuário, v. 16, n. 174, p. 5-11; $30-37,1992$.

ZHANG, J.; LIU, J.; YANG, C.; DU, S.; YANG, W. Photosynthetic performance of soybean plants to water deficit under high and low light intensity. South African Journal of Botany, v. 105, p. $279-287,2016$.

License information: This is an open-access article distributed under the terms of the Creative Commons Attribution License (type CC-BY), which permits unrestricted use, distribution and reproduction in any medium, provided the original article is properly cited. 